\title{
Da ética à prática da solidariedade segundo a Laudato Si
}

\author{
From ethics to the practice of solidarity according to Laudato Si
}

\author{
Moisés Furmann ${ }^{1}$ \\ Olmaro Paulo Mass ${ }^{2}$
}

\begin{abstract}
Se o ser humano se declara autónomo da realidade e se constitui dominador absoluto, desmorona-se a própria base da sua existência, porque em vez de realizar o seu papel de colaborador de Deus na obra da criação, o homem substitui-se a Deus, e deste modo acaba por provocar a revolta da natureza3.
\end{abstract}

\section{Resumo}

Refletir sobre a prática da solidariedade pelo viés do cuidado e da ética exige destacar que devemos perceber o paradigma da globalização e o modelo tecnocrático de desenvolvimentos e os impactos na vida social dos indivíduos e sua relação com o meio ambiente. O documento papal traz presente a categoria do cuidado comum, como algo essencial em vista do desenvolvimento integral sustentável e, por outro lado, estabelece uma relação com a "casa comum” que perpassa pelo percurso ético e espiritual, que possibilita uma relação madura, responsável e solidária com os bens da criação, como também, o cuidado com os mais pobres. Portanto, uma espiritualidade solidária e ética possibilita estabelecer uma nova relação de cuidado com a mãe terra acompanhado por crescentes atitudes de mudanças e de novos hábitos saudáveis de consumo.

Palavras-Chave: Ética; Teologia; Religião; Bem Comum; Ecologia.

\begin{abstract}
Reflecting on the practice of solidarity through the care and ethics bias requires highlighting that we must understand the paradigm of globalization and the technocratic model of developments and the impacts on the social life of individuals and their relationship with the environment. The papal document brings to mind the category of common care, as something essential in view of sustainable integral

\footnotetext{
${ }^{1}$ Mestrando em Teologia - Escola de Humanidades - PUCRS.

E-mail: mfurmann@hotmail.com.

2 Doutor em Filosofia - UNISINOS.

E-mail: olmaro2017@gmail.com.

3 FRANCISCO, Papa. Laudato Si, parágrafo 117. (Nas próximas referência será abreviado, a exemplo: $L S$ 117)
} 
development and, on the other hand, establishes a relationship with the "common home" that runs through the ethical and spiritual path, which enables a mature, responsible relationship and in solidarity with the goods of creation, as well as caring for the poorest. Therefore, a solidary and ethical spirituality makes it possible to establish a new care relationship with mother earth accompanied by growing attitudes of changes and new healthy consumption habits.

Keywords: Ethic; Theology; Religion; Very common; Ecology.

\section{Considerações Iniciais}

A presente reflexão pretende abordar o tema da discursividade da ética do cuidado da "casa comum", em relação ao conceito de solidariedade na Encíclica Laudato Si, tendo-se presente a abrangência do documento e a complexidade das diversificadas dimensionalidades que tocam à vida e que são abordadas, sobretudo no contexto da pandemia, tem uma contribuição significativa e amplamente discutida nos meios acadêmicos e entre ambientalistas. Mas, refletir sobre a relação entre ética e solidariedade é um árduo caminho a ser traçado, principalmente no que concerne às contribuições do documento, em relação ao conceito de ecologia integral e de liberdade, que Francisco coloca em diálogo com vários outros conceitos correlacionados e intrinsecamente já presentes em outros documentos papais. E, consequentemente, outros temas teológicos e filosóficos que, com sua proposição, necessariamente colidem frontalmente com propostas distintas, tais como a de desenvolvimento sustentável e suas implicações e possíveis limitações no modelo do capitalismo financeiro hodierno. Esse modelo de tardo-capitalismo é determinante sobre as formas de relações estabelecidas com a casa comum e os impactos sobre o meio ambiente. Esse modelo de sustentabilidade que tem suas raízes no pensamento iluminista 4 é colocado em xeque diante das recorrentes crises do capitalismo industrial e financeiro, que vem à tona e acentua-se com a pandemia, que assola a realidade mundial em seus aspectos sociais, políticos e econômicos, ambientais e humanitários.

\footnotetext{
4 É importante salientar as principais ideias kantianas que expressam o objetivo, a meta e o sentimento iluminista: é a saída do ser humano da sua imaturidade intelectual e essa imaturidade, para ele, significa a incapacidade da pessoa servir-se do próprio entendimento, de sua razão para buscar a emancipação política e social e construir-se como sujeito autônomo. "Esclarecimento (Aufklãrung) é a saída do homem de sua menoridade, da qual ele próprio é culpado. A menoridade é a incapacidade de fazer uso de seu entendimento sem a direção de outro indivíduo' (KANT, Emmanuel. Resposta à pergunta: que é esclarecimento (Aufklãrung)?, 1974. p. 100).
} 
Em primeiro lugar, cabe salientar, que o momento histórico interfere na leitura da realidade e é acentuada pelo Papa Francisco, depois de cinco anos da publicação do documento em suas homilias e catequeses. Esta condição estará também presente na leitura da Encíclica Laudato Si, pois os pontos relevantes do documento, mesmo que a realidade apresente novas situações, pode-se dizer que o texto é atual e instiga a reinterpretação, sobretudo nesse contexto de pandemia. Por isso, cabe indagar: É possível traduzir as implicações ético-ecológicas do discurso teológico a partir dos principais questionamentos levantados no documento? Como as questões sociais estão implicadas no discurso teológico enquanto proposta de construção de um mundo mais solidário e sustentável para que todos tenham vida, e a tenham em abundância (Jo 10,10)?

A postura assumida pela Igreja na América Latina 5 , em Puebla, toma o partido dos pobres e decide o seu lugar social para ler a realidade 6 , a partir deste ponto referencial que o Papa Francisco toca constantemente como uma preocupação essencial. Esta leitura possibilita-lhe visualizar que o pobre é fruto de uma estrutura opressora e, por consequência, é quem mais sofre com esse modelo tecnocrático de exploração da natureza.

Desta forma, o trabalho pretende buscar os fundamentos éticos presentes no documento Laudato Si para refleti-los na teologia pública, que resgata o sentido da fé na sociedade pós-moderna orientada pelo sistema técnico científico, consumista, individualista e antropocêntrico. O contexto exige refletir as vias essenciais para

\footnotetext{
5 Uma leitura fundamental é de Hugo Córdova que destaca a importância do diálogo e pluralismo religioso que temos na América Latina com suas diferenças que enriquem o pensamento cristão, mas também o desafio da valorização daquilo que é próprio e específico da cultura. O respeito e diálogo é necessário: "O pluralismo religioso na América Latina oferece um importante desafio à compreensão e desenvolvimento de uma teologia pública não centrada no cristianismo. É uma realidade que, devido à sua história de colonização, tanto pelo império espanhol como português, o cristianismo, especialmente o catolicismo romano, tem sido predominante nas sociedades, na política e no meio das culturas latino-americanas. Podemos falar de um "passado colonial" tanto nas sociedades seculares como na religião cristã. Os conquistadores trataram violentamente os povos nativos que foram julgados como "idólatras" e forçados a assumir a nova religião cristã" (QUERO, Hugo Córdova, 2016, p. 67)

${ }^{6}$ Outras discussões e preocupações que sutilmente estão na Laudato Si, mas que a Igreja na América Latina tem se debruçado como preocupação no processo de evangelização são as chamadas teologias pós-coloniais que se deram no processo de ocidentalização muito bem trazidas por Claudio Carvalhaes: "Assim, o pensamento pós-colonial pensa a partir das marginalidades da sociedade e suas formas de resistência, e busca nessas vozes/comunidades/movimentos, intervir, sacudir, delimitar, alterar, romper com processos políticos e sociais de poder que tentam calar a voz e os corpos dos pobres, sua honra e autonomia, possibilidade de luta, honra e libertação. Assim, se busca a presença de mulheres, indígenas, negros/negras, pessoas não heterossexuais e os pobres como sujeitos históricos que nos ajudem a fortalecer, repensar e recriar formas de pensamento e práticas de resistência" (CARVALHAES, Claudio. Teologia pública e pós-colonialismo, 2016, p. 29)
} 
despertar nas comunidades dos diversos segmentos o florescimento de novas ideias em torno à ética do cuidado. Assim, busca-se atingir seu objetivo ao discutir as propostas apresentadas pelas comunidades, a partir do diálogo respeitoso de uns com os outros, e com as forças do ecossistema do qual fazemos parte. Hoje, temos que levar em conta os elementos da crise político-econômica-social, que atinge os mais pobres, os vulneráveis das periferias dos grandes centros urbanos e demais situações que surgem com a pandemia.

\section{Posições Críticas e a Necessidade de uma Ética da Solidariedade}

Quando Aristóteles observa que o homem é por natureza um animal político está reafirmando categoricamente que somos seres de relações e, que, necessitamos desenvolver uma ética do cuidado e do bem comum. Assim, podemos asseverar: como seres de relações, a espiritualidade está intrínseca e interligada com a forma de conviver, de ser, de existir e de cuidar. O Papa Francisco na 'Laudato Si' (traduzido 'Sobre o cuidado da Casa comum') traz presente que a espiritualidade do cuidado é uma forma completa de viver o amor de Deus, que se dá na relação com a 'casa comum' e na inserção como sujeitos políticos e práticos. Para isso, faz-se necessário criar com a 'casa comum' uma reciprocidade que respeite o meio ambiente e sua diversidade, desenvolvendo hábitos saudáveis, numa relação de sustentabilidade equilibrada. Por outro lado, o tema da ecologia integral e da espiritualidade do cuidado faz repensar nossas relações de amor pelas maravilhas da criação, já expressada por Francisco de Assis no "Cântico das Criaturas", retratando a biodiversidade existente no planeta: louvado seja pelo irmão fogo, irmão vento, pelo sol e pela irmã terra e por todos os frutos diversos que nos alimentam diariamente.

Ao articular a relação entre ecologia integral e a ética da solidariedade à crítica ao antropocentrismo, observa que as grandes mudanças ocorridas na ciência e na tecnologia contribuíram de forma significativa para um novo modo de relacionar-se com os bens materiais, desenvolvendo novos hábitos de consumo que, aos poucos, foram introduzidos na vida das pessoas, criando-se uma cultura do descartável, do descuido, afetando diretamente a vida na 'casa comum'. Os efeitos da industrialização moderna, chamados por Francisco de 'globalização do paradigma tecnocrático' e do consumo, desencadeou a crise ética, moral e de 
sustentabilidade da "casa comum", visto que, as novas tecnologias influenciam diretamente no modo de ser, de conviver e de se relacionar com os bens da criação. Essa forma da relação entre o homem e os bens da criação levaria a uma harmonia e ao cuidado em contraposição ao antropocentrismo desordenado:

\begin{abstract}
Quando o pensamento cristão reivindica, para o ser humano, um valor peculiar acima das outras criaturas, suscita a valorização de cada pessoa humana e, assim, estimula o reconhecimento do outro. A abertura a um « tu » capaz de conhecer, amar e dialogar continua a ser a grande nobreza da pessoa humana. Por isso, para uma relação adequada com o mundo criado, não é necessário diminuir a dimensão social do ser humano nem a sua dimensão transcendente, a sua abertura ao « Tu » divino. Com efeito, não se pode propor uma relação com o ambiente, prescindindo da relação com as outras pessoas e com Deus. Seria um individualismo romântico disfarçado de beleza ecológica e um confinamento asfixiante na imanência.7
\end{abstract}

Sua crítica aponta o restrito modelo de desenvolvimento sustentado tão somente no crescimento econômico. E concebe um sujeito tecnocrático ${ }^{8} \mathrm{e}$ antropocêntrico, que se apropria do que está fora dele. Este sujeito estabelece o método científico de sua posse para dominar e transformar ( $L S 106)$. O crescimento econômico ultrapassa os limites do razoável e de uma consciência ecológica. Com efeito, Francisco destaca que na sociedade de risco, o impacto da globalização póstradicional trouxe transformações na vida cotidiana para as classes sociais, embora não resolvesse os principais problemas que afligem a nossa sociedade, desde os tempos mais remotos, como: combate à fome, saneamento básico e moradia, distribuição de renda, acesso à tecnologia, etc. A ciência moderna, que proporcionou a era tecnológica e do progresso, passa a ser considerada como fonte de autodestruição da natureza e que está a serviço de um modelo econômico insustentável para a atualidade. Essa atitude de mudança possibilita pensar uma prática inovadora, mas responsável, solidária e de cuidado comum, ou seja, um ser humano novo: "Se a crise ecológica é uma expressão ou uma manifestação externa da crise ética, cultural e espiritual da modernidade, não podemos iludir-nos de

\footnotetext{
7 FRANCISCO, Papa. Laudato Si, parágrafo 119.

${ }^{8}$ No parágrafo 109 , da Laudato $S i$, o domínio do paradigma tecnocrático sobre a economia e a política. "O paradigma tecnocrático tende a exercer o seu domínio também sobre a economia e a política. A economia assume todo o desenvolvimento tecnológico em função do lucro, sem prestar atenção a eventuais consequências negativas para o ser humano. A finança sufoca a economia real. Não se aprendeu a lição da crise financeira mundial e, muito lentamente, se aprende a lição do deterioramento ambiental. Nalguns círculos, defende-se que a economia actual e a tecnologia resolverão todos os problemas ambientais, do mesmo modo que se afirma, com linguagens não académicas, que os problemas da fome e da miséria no mundo serão resolvidos simplesmente com o crescimento do mercado.”
} 
sanar a nossa relação com a natureza e o meio ambiente, sem curar todas as relações humanas fundamentais" ( $L S$ 119).

No documento e nas suas reflexões, Francisco observa atentamente e de forma minuciosa o sistema capitalista de produção e de desenvolvimento econômico que se sustenta na destruição da "casa comum" e à custa de trabalhadores, que são explorados nos trabalhos oferecidos, os quais cada vez mais perdem seus direitos conquistados. Aborda o paradigma tecnocrático dominante, que nos põe diante de enormes encruzilhadas: por um lado, o entusiasmo do progresso, que imprimiu um gradual modelo de estupenda e impressionante capacidade da humanidade de usufruir dos bens produzidos e, por outro lado, [...] "ele está nu e exposto diante do seu poder que continuar a crescer" ( $L S$ 82), em uma época que já se tem consciência que os recursos naturais não são ilimitados, mas escassos e muitos deles insuficientes para suprir as necessidades das pessoas. Deste modo, compreende-se que a intervenção do ser humano sobre a natureza é puramente de interesses e não de um modelo econômico sustentável que visa o cuidado comum.

Por outro lado, frente ao cenário atual, com este paradigma tecnocrático busca-se compreender as consequências e o impacto sobre o meio ambiente, que é de responsabilidade de todos. Por isso, a consciência crítica deve fazer parte das políticas públicas educacionais, movimentos sociais, comunidades de base e demais agentes sociais, preocupados em desenvolver iniciativas que contribuam para um agir ético, solidário e responsável do cuidado da 'casa comum'. Nesse sentido, é fundamental ter-se presente os limites e suas condições de estabelecer uma relação do cuidado mais responsável, visando a solidariedade, haja vista que somos partícipes da criação. Conforme destaca o pontífice, isso implica capacidade de conhecer a verdade, ter vontade de mudança, juntamente com a liberdade, porém com responsabilidade.

Uma ciência, que pretenda oferecer soluções para os grandes problemas, deveria necessariamente ter em conta tudo o que o conhecimento gerou nas outras áreas do saber, incluindo a filosofia e a ética social. Mas este é atualmente um procedimento difícil de seguir. Por isso também não se consegue reconhecer verdadeiros horizontes éticos de referência. A vida passa a ser uma rendição às circunstâncias condicionadas pela técnica, entendida como o recurso principal para interpretar a existência. $\mathrm{Na}$ realidade concreta que nos interpela, aparecem vários sintomas que mostram o erro, tais como a degradação ambiental, a ansiedade, a perda 
do sentido da vida e da convivência social. Assim se demonstra uma vez mais que a realidade é superior à ideia. 9

A perspectiva do documento aproxima-nos das diferentes investigações sobre as questões ambientais e outras situações concretas que a sociedade precisa refletir, mas também com as possíveis soluções apresentadas, que exigem tomadas de decisões que sejam mais coletivas e responsáveis que, na visão do Papa, vem ao encontro de um modelo de desenvolvimento global. Isso implica um diálogo aberto e respeitoso, visto que a humanidade passou por vários processos de mudança e continua a redescobrir formas de adaptação às novas realidades. As crises podem nos educar, mesmo que sejam doloridas e complexas de serem resolvidas, com estratégias que vêm ao encontro de soluções que visem o cuidado da "casa comum".

Por um lado, os que defendem o "mito do progresso" afirmam que os problemas ecológicos só podem ser resolvidos com novas aplicações técnicas, "sem considerações éticas nem mudanças de fundo" ( $L S, 60)$. Outros têm uma compreensão estrita, por isso, fazem a leitura de que toda intervenção humana ameaça e compromete o ecossistema mundial, parecendo-lhes conveniente reduzir a sua presença no planeta, impedindo todo tipo de intervenção humana. Por isso, Francisco acentua e tem uma compreensão mais aberta ao ler a realidade em vista de perceber que não existe só um caminho de solução, mas que urge ser identificados os possíveis cenários futuros, com a contribuição de todos, a partir do diálogo para se chegar a respostas abarcantes, compreensíveis e consistentes ( $L S$, $60)$.

O ser humano não é plenamente autônomo. A sua liberdade adoece, quando se entrega às forças cegas do inconsciente, das necessidades imediatas, do egoísmo, da violência brutal. Neste sentido, ele está nu e exposto frente ao seu próprio poder que continua a crescer, sem ter os instrumentos para o controlar. Talvez disponha de mecanismos superficiais, mas podemos afirmar que carece de uma ética sólida, uma cultura e uma espiritualidade que lhe ponham realmente um limite e o contenham dentro dum lúcido domínio de si. ${ }^{10}$

Assim, vivenciar a ética da solidariedade e do cuidado comum, enquanto dimensão de vitalidade, de sentido e de integridade, influencia diretamente novos modos e estilos de vida, para superar um modelo econômico e das estruturas consolidadas de poder que não visam o bem comum e o cuidado do planeta. São

\footnotetext{
9 FRANCISCO, Papa. Laudato Si, parágrafo 110.

${ }^{10}$ FRANCISCO, Papa. Laudato Si, parágrafo 105. 
modelos de crescimento que parecem ser 'incapazes de garantir o respeito ao meio ambiente' e à biodiversidade. Na compreensão do Papa Francisco, o mercado, por si mesmo, não garante o desenvolvimento humano integral nem a inclusão social, principalmente dos mais pobres (LS 109). Enfim, possibilitar a ética da solidariedade exige mudanças nas formas de se relacionar e cuidar da casa comum, levando em conta os paradigmas da globalização e os principais desafios em vista de um desenvolvimento sustentável dos princípios da ecologia integral.

Cabe destacar que o desafio é repensar a relação entre sustentabilidade, economia globalizada e cuidado comum, respeitando a biodiversidade e as diversas formas de vida. Cabe avultar e identificar três pontos cruciais que devem fazer parte da relação entre ecologia integral e espiritualidade: discutir as novas relações de hábitos de consumo; modos de se relacionar com a natureza (casa comum) e, assim, provocar reflexões multidimensionais que visem alternativas viáveis em vista de despertar pequenas iniciativas que ajudem as pessoas em vista do cuidado comum na relação com o meio ambiente.

\section{Da ética da solidariedade ao discurso prático}

Há mais de cinquenta anos, após o Concílio Vaticano II, a Igreja vem se manifestando de modo mais contundente sobre as questões sociais, mudando o foco das discussões e posicionamentos, como, por exemplo, do antimodernismo ${ }^{11}$ aos problemas que afligem o mundo, como a Encíclica Pacem in terris ${ }^{12}$ e a segunda parte da Gaudium et Spes $^{13}$. A Igreja reflete as problemáticas modernas, procurando

\footnotetext{
${ }^{11}$ Conforme o Wikipedia, este é o posicionamento da Igreja diante do modernismo: "O Papa Pio X, que defendia intransigentemente a ortodoxia doutrinária, condenou fortemente o modernismo, que é encarado por ele como a "síntese de todas as heresias". Esta sua veemente condenação está expressa, por exemplo, nos documentos Lamentabili Sane (1907) e Pascendi Dominici Gregis (1907). Indo mais longe, este Papa formulou inclusivamente o "juramento antimodernista", obrigatório para todos os padres, bispos, catequistas e seminaristas." (fonte Wikipedia, in site: https://pt.wikipedia.org/wiki/Modernismo_(teologia).

${ }^{12}$ Pacem in Terris, do Papa João XXIII, é uma Encíclica da doutrina social da Igreja que reflete os direitos e os deveres da pessoa humana, a relação do indivíduo com os poderes públicos e as comunidades políticas procurando fundamentos para a paz. Para se aprofundar sobre a Encíclica indicamos o site: https://pt.wikipedia.org/wiki/Pacem in Terris.

${ }^{13} \mathrm{Na}$ Gaudium et Spes, docomunto do Concílio Vaticano II, temos sinais concretos de mudança no modo de posicionamento da Igreja Católica, conforme o parágrafo 76: "No domínio próprio de cada uma, comunidade política e Igreja são independentes e autônomas. Mas, embora por títulos diversos, ambas servem a vocação pessoal e social dos mesmos homens. E tanto mais eficazmente exercitarão este serviço para bem de todos, quanto melhor cultivarem entre si uma sã cooperação, tendo igualmente em conta as circunstâncias de lugar e tempo. Porque o homem não se limita à ordem temporal somente; vivendo na história humana, fundada sobre o amor do Redentor, ela contribui para que se difundam mais amplamente, nas nações e entre as nações, a justiça e a
} 
vislumbrar soluções a partir das comunidades. No ano de 1971, Papa Paulo VI, exortava acerca da possibilidade de uma catástrofe ecológica, devido à explosão da civilização industrial. Ressaltava, além disso, a necessidade de mudança radical no comportamento da humanidade diante do progresso científico, tecnológico e econômico que deveriam ocorrer unidos ao progresso social e moral sem o qual os demais poderiam se voltar contra o próprio ser humano $(L S, 4)$.

A Encíclica Laudato Si apresentada por Papa Francisco, em 2015, inspira entrar em diálogo, tendo como referência essencial o tema da casa comum $(L S, 3)$. Seguindo os passos de João XXIII, na Encíclica Pacem in Terris, não restringe o documento somente aos católicos, mas procurou dirigir-se a todas as "pessoas de boa vontade". Nessa direção, Francisco manifesta: "quero dirigir-me a cada pessoa que habita neste planeta" $(L S, 3)$. O documento destaca a preocupação da Igreja com a destruição do ambiente humano e consequentemente a degradação da vida humana $(L S, 5)$. A ecologia integral, segundo Francisco, é inspirada em São Francisco, considerado exemplo por excelência do cuidado pelo que é frágil $(L S, 10)$. Nasce, assim, o convite a uma conversão ecológica global, abarcando a totalidade do ecossistema que possibilita à vida no planeta e no cosmos.

Por isso, podemos afirmar que o documento pontifício gira em torno de estabelecer condições plausíveis para os alicerces da ética do cuidado, frente ao sistema vigente, que coloca o homem moderno como centro do universo, em que a razão e a técnica têm uma postura de superioridade sobre as demais formas de relações e de conhecimentos. Nesse sentido, o documento papal tem contribuições significativas em vista de perceber-se que os limites da modernidade devem passar pelo crivo de uma autocrítica, atitude necessária para qualquer forma de conhecimento proposta para uma nova ética civilizacional. Ou seja, o sonho iluminista e da ciência moderna chamado pelo papa de "prometeico de domínio sobre o mundo", assentado a partir de um antropocentrismo desordenado e centralizado na racionalidade instrumentalizada, tem implicâncias diretas sobre as formas de disposição, de uso, de valorização e de responsabilidade sobre os rumos da casa comum. Uma ética do cuidado passa princípios da ecologia integral e social e a inter-relação de múltiplas formas de conhecimento e de experiências, que

caridade. Pregando a verdade evangélica e iluminando com a sua doutrina e o testemunho dos cristãos todos os campos da atividade humana, ela respeita e promove também a liberdade e responsabilidade política dos cidadãos." 
valorizem uma visão mais sistêmica de totalidade e de formas de relacionar-se com a casa comum, condição essencial para o diálogo e para o estabelecimento de um novo ethos.

\begin{abstract}
Por que motivo incluir, neste documento dirigido a todas as pessoas de boa vontade, um capítulo referido às convicções de fé? Não ignoro que alguns, no campo da política e do pensamento, rejeitam decididamente a ideia de um Criador ou consideram-na irrelevante, chegando ao ponto de relegar para o reino do irracional a riqueza que as religiões possam oferecer para uma ecologia integral e o pleno desenvolvimento do género humano; outras vezes, supõe-se que elas constituam uma subcultura, que se deve simplesmente tolerar. Todavia a ciência e a religião, que fornecem diferentes abordagens da realidade, podem entrar num diálogo intenso e frutuoso para ambas. ${ }^{14}$
\end{abstract}

As condições apontadas no documento sobre as possibilidades da ecologia integral em contraponto à globalização do paradigma tecnocrático somente são possíveis quando tivermos políticas públicas sérias e comprometidas com um modelo econômico sustentável que valorize os princípios do bem comum, que é a ética da solidariedade e do cuidado. Pensar em soluções significa avançar na problematização e fazer uma reflexão sobre as raízes da crise ambiental.

É impossível chegar-se a uma premissa e a um consenso se prevalecem, em primeiro plano, os interesses econômicos. Não se pode dissociar a questão dos alimentos e da alimentação saudável do debate sobre as questões ambientais e animais, e das demais formas de vida e ecossistemas, se pretende um mínimo de equilíbrio e harmonia no planeta terra. Tudo está interligado e, segundo Francisco, ao referir-se à ecologia integral e sustentável a partir de uma relação social que visa o bem comum, devemos ter em mente que: "isto exige sentar-se a pensar e discutir acerca das condições de vida e de sobrevivência duma sociedade, com a honestidade de pôr em questão modelos de desenvolvimento, produção e consumo. Nunca é demais insistir que tudo está interligado" $(L S, 107)$.

Necessitamos criar hábitos culturais conscientes e responsáveis com o ecossistema do nosso planeta. O consumo consciente é vital para que a humanidade possa criar um modelo de economia solidária. Portanto, precisamos repensar as bases das relações de mercado que são meramente baseadas na lógica de acúmulo. A educação ambiental pode contribuir no campo pedagógico para refletir-se de forma crítica sobre as mudanças culturais e sociais que ocorrerem no planeta e, por outro lado, para lutar-se por políticas púbicas comprometidas que promovam um

14 FRANCISCO, Papa. Laudato Si, parágrafo 62.

Opinião Filosófica - ISSN: 2178-1176 - Editora Fundação Fênix. www.fundarfenix.com.br 
modelo de desenvolvimento sustentável. Trata-se de compreender, na ótica de Francisco, que:

\begin{abstract}
A cultura ecológica não se pode reduzir a uma série de respostas urgentes e parciais para os problemas que vão surgindo à volta da degradação ambiental, do esgotamento das reservas naturais e da poluição. Deveria ser um olhar diferente, um pensamento, uma política, um programa educativo, um estilo de vida e uma espiritualidade que oponham resistência ao avanço do paradigma tecnocrático ${ }^{15}$.
\end{abstract}

A educação precisa traduzir-se em novos hábitos de vida que levam as pessoas a um consumo solidário e consciente. É um processo de (re)educação das formas da injustiça e de opressão econômica e social. Uma espiritualidade que promova uma nova qualidade de vida e de um agir sóbrio das múltiplas formas de estabelecer uma comunhão fraterna com a casa comum. Ora, trata-se de criar uma responsabilidade ética teológica da responsabilidade solidária para com o "cuidado comum da casa”, em vista de termos a capacidade de criar condições que vão ao encontro de ações de um modelo de desenvolvimento, de produção de bens que sejam sustentáveis. O desafio está posto, que, segundo Francisco, "É «o conjunto das condições da vida social que permitem, tanto aos grupos como a cada membro, alcançar mais plena e facilmente a própria perfeição»" ( $L S$, 120 ).

Por isso, cabe estabelecer um diálogo em vista de buscar estabelecer os traços de uma ética do cuidado, presente no documento papal, para repensar o contexto hodierno em que as iniciativas e as práticas dos diversos saberes estão fragmentadas, distanciando-se de uma visão mais integrada e responsável para possibilitar um equilíbrio entre consumo responsável e ecologia integral. Essa compreensão supõe, nos dias atuais, assimilar os principais problemas e situações em relação às questões ambientais. Supõe que isso, "é inseparável da análise dos contextos humanos, familiares, laborais, urbanos, e da relação de cada pessoa consigo mesma, que gera um modo específico de relacionamento com os outros e com o meio ambiente" $(L S, 141)$. Um segundo ponto refere-se à questão da desigualdade planetária, na qual os pobres são os mais vulneráveis: frágeis e que sofrem as consequências da "deterioração do meio ambiente e da sociedade, afeta de modo especial os mais frágeis do planeta" ( $L S$,

15 FRANCISCO, Papa. Laudato Si, parágrafo 87. 
48). Outro elemento a destacar, dentro desse contexto, é o conceito de felicidade relacionado com o estilo de vida adotado e imposto aos indivíduos, que vai na contramão ao cuidado comum e o consumo consciente e responsável. Por fim, o desequilíbrio ético e solidário entre natureza e homem exige uma nova releitura e compreensão do papel do ser humano em relação ao Criador, pois como criatura e partícipe, integra-se na relação entre ecologia integral e dos processos históricos a que pertence. Assim, urge o desafio posto no livro de Gênesis $(2,15)$ na relação entre cuidar e guardar: "A harmonia entre o Criador, a humanidade e toda a criação foi destruída por termos pretendido ocupar o lugar de Deus, recusando reconhecer-nos como criaturas limitadas" $(L S, 66)$.

\section{Espiritualidade Solidária e a Fé}

Na Encíclica Lumen Fidei ${ }^{16}$ a fé é apresentada como luz que dissipa as trevas e ilumina o ser humano como é. No segundo parágrafo, apresenta o desafio moderno à fé, apontando para a possibilidade de que a luz emanada da fé poderia ter sido suficiente às sociedades antigas. E não serviria para os novos tempos, para o homem tornado adulto ufanar-se da razão que pretende explorar de forma nova o futuro. Esta perspectiva da fé diz que sua luz é ilusória e impede ao homem cultivar a ousadia do saber $(L F, 2)$.

O jovem Nietzsche convidava a irmã Elisabeth a arriscar, percorrendo vias novas (...), na incerteza de proceder de forma autónoma ». E acrescentava: « Neste ponto, separam-se os caminhos da humanidade: se queres alcançar a paz da alma e a felicidade, contenta-te com a fé; mas, se queres ser uma discípula da verdade, então investiga ». [3] O crer opor-se-ia ao indagar. Partindo daqui, Nietzsche desenvolverá a sua crítica ao cristianismo por ter diminuído o alcance da existência humana, espoliando a vida de novidade e aventura. Neste caso, a fé seria uma espécie de ilusão de luz, que impede o nosso caminho de homens livres rumo ao amanhã. ${ }^{17}$

\footnotetext{
${ }^{16}$ A encíclica Lumen Fidei - Luz da Fé (no texto passaremos a usar a sigla $L F$ para citar esta encíclica) é a primeira encíclica do Papa Francisco, publicada em julho de 2013. "A encíclica centra a sua temática na fé e conclui uma trilogia de seu predecessor, o Papa Bento XVI, que já havia escrito sobre a esperança e a caridade, as outras virtudes teologais, nas encíclicas: Deus Caritas Est, Spe Salvi e Caritas in Veritate. Francisco assumiu, de fato, o trabalho de Bento XVI que, antes de sua renúncia ao papado, já tinha completado o primeiro rascunho do texto, ao qual foram adicionadas algumas contribuições do papa argentino." (Fonte do site: https://pt.wikipedia.org/wiki/Lumen fidei, acessado dia 20 de junho de 2020.)

${ }_{17}$ FRANCISCO, Papa. Lumen Fidei, parágrafo 2.
} 
Esta perspectiva convive com a luz da razão e associa a fé à escuridão, ganhando espaço onde a razão não podia iluminar e não garantia certezas para o homem. A fé passa a ser considerada um salto no vazio impulsionado pelo sentimento cego, luz subjetiva capaz de aquecer e consolar o coração. Aos poucos, percebe-se que a luz da razão autônoma não consegue iluminar assaz o futuro, deixando o homem no temor do desconhecido. Consequentemente, o homem abandona a busca por uma luz, uma verdade grande e "se contenta com pequenas luzes que iluminam por breves instantes”, mesmo que não consiga iluminar a estrada para identificar o caminho e distinguir o bem do mal. $(L F, 2)$.

\begin{abstract}
Lembrar esta ligação da fé com a verdade é hoje mais necessário do que nunca, precisamente por causa da crise de verdade em que vivemos. Na cultura contemporânea, tende-se frequentemente a aceitar como verdade apenas a da tecnologia: é verdadeiro aquilo que o homem consegue construir e medir com a sua ciência; é verdadeiro porque funciona, e assim torna a vida mais cómoda e aprazível. Esta verdade parece ser, hoje, a única certa, a única partilhável com os outros, a única sobre a qual se pode conjuntamente discutir e comprometer-se; depois haveria as verdades do indivíduo, como ser autêntico face àquilo que cada um sente no seu íntimo, válidas apenas para o sujeito mas que não podem ser propostas aos outros com a pretensão de servir o bem comum..$^{18}$
\end{abstract}

A fé cristã anuncia a verdade do amor total de Deus, chegando ao centro da experiência de cada homem. O encontro do cristianismo com o mundo grego, desejoso da busca pela verdade, possibilitou o diálogo entre fé e razão, de forma profícua e fecunda. A luz da fé procura iluminar nossas relações humanas, as quais podem ser vividas em união com o amor e a ternura de Cristo ( $L F 32$ ). A verdade que se mostra no encontro com o Outro e com os outros corrobora na superação de certa oposição entre fé e razão, entre crer e interrogar, não se fixando numa segurança, possibilitando o diálogo que desperta o sentido crítico, alargando horizontes ( $L F 34$ ). A verdade faz com que o crente não seja arrogante e endurecido, pois a fé ${ }^{19}$ abre caminho e torna possível o testemunho e o diálogo com todos.

\footnotetext{
${ }^{18}$ FRANCISCO, Papa. Lumen Fidei, parágrafo 25.

${ }^{19} \mathrm{Na}$ Lumen Fidei, a fé e a ciência são apresentadas da seguinte forma no parágrafo 34: "[...] enquanto unida à verdade do amor, a luz da fé não é alheia ao mundo material, porque o amor vivese sempre com corpo e alma; a luz da fé é luz encarnada, que dimana da vida luminosa de Jesus. A fé ilumina também a matéria, confia na sua ordem, sabe que nela se abre um caminho cada vez mais amplo de harmonia e compreensão. Deste modo, o olhar da ciência tira benefício da fé: esta convida o cientista a permanecer aberto à realidade, em toda a sua riqueza inesgotável. A fé desperta o sentido crítico, enquanto impede a pesquisa de se deter, satisfeita, nas suas fórmulas e ajuda-a a compreender que a natureza sempre as ultrapassa. Convidando a maravilhar-se diante do mistério da criação, a fé alarga os horizontes da razão para iluminar melhor o mundo que se abre aos estudos da ciência."
} 
O respeito da fé pela razão pede para se prestar atenção àquilo que a própria ciência biológica, desenvolvida independentemente dos interesses econômicos, possa ensinar a propósito das estruturas biológicas e das suas possibilidades e mutações. Em todo o caso, é legítima uma intervenção que atue sobre a natureza para a ajudar a desenvolver-se na sua própria linha, a da criação, querida por Deus. ${ }^{20}$

Para Comblin, o mistério de Deus só é perceptível ao ser humano pela participação no mesmo, obtido não só pela conclusão que tiramos da contemplação, pois é parte do mistério que dá acesso à verdadeira liberdade. E não mero objeto de contemplação inerte, mas por estarmos estreitamente implicados nele. "[...] um único ato de fé nos faz descobrir num mesmo olhar a visão do desígnio de Deus na totalidade da criação e a visão da nossa existência limitada dentro dessa totalidade.” ${ }^{21}$ Assim, Comblin afirma que ter fé é aceitar a Palavra viva aplicada e interpretada pelo Espírito, pois a letra morta concentra-se somente na 'letra' e no entusiasmo da mente humana, sem chegar ao verdadeiro significado revelado pelo Espírito. A fé verdadeira não é passiva e sabe interpretar as situações da vida individual e social à luz da revelação de Cristo. A fé é dinâmica, não sendo algo estável e garantido, mas necessita de constante renovação dos conteúdos e das fórmulas. ${ }^{22}$

Hoje em dia, mais do que nunca, as pessoas sentem necessidade de compreender o significado da própria ação. Ora, interpretar a ação é ao mesmo tempo relacioná-la com a totalidade do real. Entre nós, muitos são os batizados e catequizados que não sabem relacionar essa ação de cada dia com o depósito da fé. A fé e a ação desenrolam-se em dois mundos paralelos que não conseguem juntarse. Para eles, também existe o problema da interpretação da ação. ${ }^{23}$

Há uma proposta de espiritualidade latente na Laudato $S i$, que nasce do "entender a qualidade de vida", da sobriedade de alegrar-se com o necessário, presente nas tradições religiosas e na Bíblia ("quanto menos, tanto mais") para superar a obsessão pelo consumismo $(L S, 222)$. É a vida simples, capaz de alegrarse com poucas coisas, centrada no bem viver integral que interliga toda a criação, da qual o ser humano é parte. Uma espiritualidade que constrói à paz no interior da pessoa, a partir do estilo de vida equilibrado, do cuidado da ecologia integral e do bem comum $(L S, 226)$. Certamente, essa proposta faz repensar o lugar do ser humano na natureza e sua relação com o outro no convívio comunitário, pois tudo

\footnotetext{
${ }^{20}$ FRANCISCO, Papa. Laudato Si, parágrafo 112, p. 72.

${ }^{21}$ COMBLIN, José. 2012, p. 32.

${ }^{22}$ COMBLIN, José. 2012, p. 51.

23 COMBLIN, José. 2012, p. 34.
} 
está interligado e o cuidado não se materializa em ações isoladas. Isto, portanto, convida-nos a maturar uma espiritualidade da solidariedade global, que brota do mistério da Trindade e impulsiona ações solidárias "entre os indivíduos da mesma geração" $(L S, 116)$.

\section{Considerações Finais}

A proposta apresentada pela Laudato Si referente à ética teológica de uma responsabilidade solidária em vista do cuidado comum busca em outras formas de relacionalidade, conhecimentos e experiências construir relações que visam o bem viver e a superação do modelo de sustentabilidade econômica às custas da destruição desordenada na natureza, que desencadeou a crise ambiental e humanitária. Por isso, o diálogo entre as ciências é necessário para o enfrentamento das situações de descaso com a mãe terra e os problemas sociais que afetam os mais pobres. Dessa forma, o objetivo colocado pelo Papa Francisco é complexo, pois supera a visão tecnocrática onde há um desequilíbrio crescente em contraponto com uma compreensão que recupere uma espiritualidade do cuidado comum e a responsabilidade ético-social com a ecologia integral.

Uma proposta de ética teológica da responsabilidade solidária quer beber de outros saberes para efetivar a realização do bem comum. E escutar linguagens outras, num mundo plural e diversificado, em uma proposta que não coloca ou o cosmos, ou Deus, ou o homem no centro, mas com uma ideia de, o homem, o cosmos e Deus chegar-se a um equilíbrio, respeitar-se a pluralidade de origem e deixar que cada uma das entidades seja ela mesma. Esta articulação desenvolve traços de solidariedade na economia com responsabilidade social e ambiental.

Outro aspecto que precisa ser considerado no desenvolvimento do conceito de ecologia integral é o antropocentrismo em que o homem em vez de cuidar e preservar a natureza se apossou dela de forma desordenada pela sua intervenção tecnocrática, afastando-se de Deus. A exemplo de São Francisco de Assis, que chama a terra de mãe, a humanidade deve voltar-se a Deus e promover uma conversão pessoal e social em vista de recriar uma consciência do cuidado e um consumo responsável e ético. "A harmonia entre criador, humanidade e toda a criação" ( $L S$ 66) foi quebrada intensamente com o advento da modernidade e precisa ser reconstruída. O caminho proposto é superar o individualismo e a visão que a 
modernidade criou de posse em que o homem torna a criação como objeto que pode ser manipulado e destruído em vista do seu bel-prazer e sem consciência crítica e de responsabilidade social.

Por fim, a contribuição do cristianismo para uma construção da ecologia integral, onde "tudo está interligado", incide em uma espiritualidade ecológica. E destaca a importância de uma visão ampliada de sociedade, para além dos cristãos, ou seja, para com os homens e mulheres de boa vontade. Isso quer dizer, fora da humanidade mesma, como antecipação do Reino, não haverá salvação. Ou salvamonos coletivamente, ou padeceremos; ou se consegue redesenhar outra humanidade, ou estaremos fadados a presenciar a autodestruição do humano ensimesmado e nos seus caprichos. Assim, a espiritualidade cristã tem aspectos que podem fazer a diferença a partir da "comum-unidade" e da fé. A primeira exige conversão ecológica, nos faz existir com o outro, sem o qual e sem a natureza não sobrevivemos. A fé não nos deixa parar, desistir, mas nos impulsiona ao esperançar, agir conforme a Carta de São Tiago, “... a fé: se não tiver obras é morta em si mesma” ( $\operatorname{Tg} 2,17$ e 2,26).

\section{Referências}

COMBLIN, José. A fé no Evangelho: meditações bíblicas. São Paulo: Paulus, 2012. - (Coleção espiritualidade bíblica)

CONFERÊNCIA NACIONAL DOS BISPOS DO BRASIL (CNBB). Diretrizes Gerais da Ação Evangelizadora do Brasil (2011-2015). São Paulo: Paulinas, 2011.

KANT, Emmanuel. Resposta à pergunta: que é esclarecimento (Aufklãrung)? In: KANT, Emmanuel. Textos Seletos. Trad. Floriano de Sousa Fernandes. Petrópolis: Vozes, 1974.

PAPA FRANCISCO. Carta Encíclica do Sumo Pontífice Francisco Laudato Si' Louvado seja. Sobre o cuidado da casa comum. Brasília: Edições CNBB, 2015.

PAPA FRANCISCO. Carta Encíclica do Sumo Pontífice Francisco Lumen Fidei' A luz $d a$ fé. Sobre a fé. 2013. In site: http://www.vatican.va/content/francesco/pt/encyclicals/documents/papafrancesco 20130629 enciclica-lumen-fidei.html, Acesso em: 22 de jun. de 2020.

PAPA FRANCISCO. Mensagem do Santo Padre Francisco para o IV dia Mundial dos Pobres. Dia 13 de junho de 2020. Disponível em: http://www.vatican.va/content/francesco/pt/messages/poveri/documents/papa- 
francesco 20200613 messaggio-iv-giornatamondiale-poveri-2020.html Acesso em: 10, jun. 2020.

QUERO, Hugo Córdova. Teologia pública e pluralismo religioso: Uma questão pendente na agenda sócio-religiosa da América Latina. In: SINNER, Rudolf von; PANOTTO, Nicolas (Org.). Teologia Pública: um debate a partir da América Latina. São Leopoldo, RS: Faculdade EST, 2016, p. 67-76.

Recebido em: 05/08/2020. Aprovado em: 12/08/2020. Publicado em: 15/08/2020. 